\title{
RESEARCH
}

\section{Neonatal outcomes by hospital of birth in Nova Scotia between 1988 and 2012: improvements in mortality and morbidity}

\author{
Carley Langley, BA ${ }^{1}$, Krista Jangaard, MD² $^{2}$ \\ 'Class of 2017, Faculty of Medicine, Dalhousie University \\ 2Departments of Pediatrics and Obstetrics and Gynaecology, Dalhousie University and \\ IWK Health Centre
}

\begin{abstract}
Objectives: (1) To describe differences in newborn outcomes with respect to hospital of birth, place of maternal residence, and time epoch for infants born in Nova Scotia between 1988 and 2012. (2) To examine the possible impacts that regionalization of maternal newborn health services between 1988 and 2012 have had on neonatal mortality rates in Nova Scotia. Methods: Data on all infants delivered in Nova Scotia between January 1, 1988 and December 31, 2012 was extracted from the Nova Scotia Perinatal Atlee Database. Infant perinatal mortality and neonatal morbidity rates were calculated in 5-year time epochs and examined by delivery hospital classification (community, regional or tertiary), and maternal driving distance from hospital. Trends by epoch, delivery hospital and driving distance were examined. Results: From 1988 to 2012 perinatal mortality rates per 1000 for all births improved at both regional (from 9.8 to 5.7/1000) and tertiary hospitals (from 12.3 to $8.1 / 1000$ ). Perinatal mortality rates for low risk births remained low and did not change significantly during this time period. Overall, neonatal morbidity rates fell across the province. Neonatal outcomes did not vary with increasing maternal distance from obstetrical services. Conclusions: Overall, infant perinatal morbidity and mortality outcomes have improved in Nova Scotia between 1988 and 2012. Regionalization of obstetrical care may have played a role in improving neonatal mortality rates among high-risk births. Increasing rural maternal isolation from obstetrical services did not impact infant perinatal mortality and morbidity outcomes when services remained available regionally.
\end{abstract}

O ver the past 25 years, both maternal characteristics and trends in obstetrical practices in Nova Scotia have changed significantly. ${ }^{1-6}$ The proportion of women delivering with a pre-pregnancy weight of $\geq 90 \mathrm{~kg}$ has increased by $165 \%$ between 1988 and 2001 alone, and the rate of women delivering over the age of 35 has also increased. 2 Differences in maternal characteristics and morbidity also exist between regions in the province. ${ }^{5}$ It has been shown that birth outcomes differ significantly based on a mother's degree of rural isolation. ${ }^{7}$ Despite the trend towards urbanization in Canada as a whole, the proportion of Nova Scotia citizens living in rural areas has not changed over the past 40 years, remaining at approximately $43 \%{ }^{8}$

In Nova Scotia rates of labour induction have increased from $18.7 \%$ to $32.7 \%$ between 1990 and 20093 and caesarian section rates have increased from 19.6\% to $27 \%$ between 1988 and $2006 .{ }^{4}$ While rates of labour induction have risen across Canada during this time period, the Canadian Institute for Health Information (2004) reports that Nova Scotia had the highest rates of induction in 2002 across all provinces, citing elective inductions for birth planning purposes for women living remote from their delivery hospital as a possible contributor. $^{11}$

Voluntary regionalization of reproductive care services in Nova Scotia was initiated between 1971 and 1983 under the guidance of the Nova Scotia Reproductive Care Program (RCP), in response to disproportionally high infant mortality rates at community and regional hospitals throughout the province. ${ }^{9}$ The regionalization process has continued throughout the past 25 years, as the number of community hospitals offering active maternity services have decreased. ${ }^{5}$ Since January of 1988, sixteen community hospitals in Nova Scotia have discontinued their intrapartum obstetrical services. Reasons for halting obstetrical services in community hospitals include changes in financial allocations, staffing, and community population dynamics.

Between 1973 and 1980, the perinatal mortality rates for births occurring in both community and regional hospitals fell drastically, from 18.4/1000 to 7.0/1000 and from 18.7/1000 to 12.2/1000 respectively.9 While the impact on newborn outcomes during the early regionalization process has been described, little is known about the more recent impacts on newborn outcomes as regionalization continues in Nova Scotia, 
despite significant changes in maternal characteristics and obstetrical practices. This research sought out to (1) describe differences in neonatal outcomes with respect to hospital of birth, place of maternal residence, and time epoch for infants born in Nova Scotia between 1988 and 2012 and (2) examine the possible impacts that regionalization of maternal newborn health services between 1988 and 2012 have had on neonatal mortality rates in Nova Scotia.

\section{Methods}

The Nova Scotia Perinatal Atlee Database (NSPAD) is a standardized, accurate and accessible database containing prospectively collected data on all pregnancies and births that have occurred in Nova Scotia since 1988. It is administered by the Reproductive Care Program (RCP) of Nova Scotia, and contains information about maternal characteristics and demographics, deliveries, and maternal and fetal outcomes. Periodic validation studies have shown the data contained within the NSAPD to be reliable. ${ }^{10,11}$ With the assistance of RCP staff, data was extracted from the NSPAD. No linkages were undertaken. Data on maternal characteristics, place of birth and maternal residence, and newborn outcomes were obtained from the NSAPD.

All Nova Scotia residents who delivered liveborn or stillborn infants between January 1, 1988 and December 31, 2012 inclusive were included in the study. Infants born weighing $<500 \mathrm{~g}$ or $<20$ weeks were excluded from this study, as these data are not recorded in the NSPAD. Our 25-year cohort included 247,391 infants.

The primary outcomes of this study include 1) rates of perinatal mortality per 1000 births, defined as the combined number of stillbirths (death of a baby before or during birth after 24 weeks gestation) and neonatal deaths (death of a baby within the first 28 days of life), and 2) rates of neonatal morbidity per 100 births, including infection (defined as positive blood cultures within the first 28 days of life), cephalohematoma and fracture, in relation to hospital of birth (community, regional or tertiary centre). Deliveries were broken into 5-year epochs for comparison purposes. Perinatal mortality and morbidity rates for all births, and low risk births (defined as singleton births, gestational age between 370 and 416, excluding major congenital anomalies) were calculated in time epochs by delivery hospital classification. Mortality and morbidity rates were also calculated by maternal distance from closest hospital offering obstetrical services, and from actual hospital of delivery, described as driving time estimates (0-30 min, 30-60 min, 60-120 min, $120+\mathrm{min}$ ) in order to investigate the impact of regionalization in relation to degree of maternal remoteness from obstetrical care services.

Continuous variables were examined by means of t-tests. Significance of mortality and morbidity rates was investigated through the use of $95 \%$ confidence intervals, and outcomes were compared using chisquared. Odds ratios were calculated for morbidity outcomes. Statistical analysis was performed using IBM SPSS Statistics for Mac version 21.

This study received ethics approval from the IWK Health Centre Research Ethics Board.

\section{Results}

Over the past 25 years, 16 community hospitals in Nova Scotia ceased the provision of intrapartum obstetrical services. The number of regional (7) and tertiary (1) hospitals offering obstetrical services has not changed. Between 1988 and 2012, the proportion of Nova Scotian infants being born at the single tertiary hospital (IWK Health Centre) has increased from $47.1 \%$ to $54.4 \%$. The proportion of infants being born at regional hospitals has also slightly increased from $42.6 \%$ to $44.7 \%$.

While there are currently no community hospitals offering planned intrapartum obstetrical services in Nova Scotia, several unplanned births occur there each year. The proportion of infants being born at community hospitals has dropped from $10.5 \%$ in 1988 to less than $0.07 \%$ by 2012 . As community hospitals stopped offering obstetrical services, women have had to travel longer distances to access maternity care. In 2012, approximately 1 in 20 women had to travel further than 1 hour to access intrapartum obstetrical care, which is an increase by more than $600 \%$ since 1988. Combined perinatal mortality rates for all births in Nova Scotia have improved significantly between 1988 and 2012 (Figure 1), dropping from 11.3 (95\% CI $10.5-12.1)$ in 1988-1992 to $7.2(6.4-8.0)$ in 2008-2012. Perinatal mortality outcomes for low risk births across the province have remained low, at $2.2(1.8$ - 2.6) from 1988-1992 and $1.9(1.5-2.4)$ in 2008-2012. These trends in perinatal mortality rates remain true for all births at both regional and tertiary hospitals.

In terms of maternal rural isolation (Table 1), infant perinatal mortality rates for all births more than doubled for women who traveled more than 60 min to their actual hospital of delivery. Infants born to women who traveled 0-60 min to their actual hospital of delivery experienced a perinatal mortality rate of 7.7 (CI 7.3 -8.1), where-as infants born to mothers who traveled more than $60 \mathrm{~min}$ had a significantly higher mortality rate $(p<0.001)$ of 18.8 (CI $17.1-20.7)$. No significant differences in infant perinatal mortality 
Table I. Perinatal mortality outcomes by maternal travel time to closest hospital offering intra-partum obstetrical services and to actual hospital of delivery

Perinatal Mortality Outcomes (All Births) by Maternal Travel Time to Closest Maternity Hospital

\begin{tabular}{|c|c|c|c|c|c|c|}
\hline \multirow{3}{*}{$\begin{array}{l}\text { Maternal Travel Time to } \\
\text { Closest Maternity Hospital }\end{array}$} & \multicolumn{6}{|c|}{ Outcome } \\
\hline & \multicolumn{2}{|c|}{ Stillbirth } & \multicolumn{2}{|c|}{ Neonatal Death } & \multicolumn{2}{|c|}{ Combined Perinatal Mortality } \\
\hline & $\mathrm{N}$ & Rate/I $000(95 \% \mathrm{Cl})$ & $\mathrm{N}$ & Rate $(95 \% \mathrm{Cl})$ & $\mathrm{N}$ & Rate $(95 \% \mathrm{Cl})$ \\
\hline $0-60 \mathrm{~min}$ & 1233 & $5.6(5.3-6.0)$ & 695 & $3.2(3.0-3.4)$ & 1928 & $8.8(8.4-9.2)$ \\
\hline $61 \min +$ & 31 & $5.9(4.2-8.4)$ & 10 & $1.9(1.0-3.5)$ & 41 & $7.8(5.8-10.6)$ \\
\hline
\end{tabular}

Perinatal Mortality Outcomes (All Births) by Maternal Travel Time to Actual Hospital of Delivery

\begin{tabular}{|c|c|c|c|c|c|c|}
\hline \multirow{3}{*}{$\begin{array}{l}\text { Maternal Travel Time to } \\
\text { Actual Hospital of Delivery }\end{array}$} & \multicolumn{6}{|c|}{ Outcome } \\
\hline & \multicolumn{2}{|c|}{ Stillbirth } & \multicolumn{2}{|c|}{ Neonatal Death } & \multicolumn{2}{|c|}{ Combined Perinatal Mortality } \\
\hline & $\mathrm{N}$ & Rate/I000 $(95 \% \mathrm{Cl})$ & $\mathrm{N}$ & Rate $(95 \% \mathrm{Cl})$ & $N$ & Rate $(95 \% \mathrm{Cl})$ \\
\hline $0-60 \mathrm{~min}$ & 1030 & $5.1(4.8-5.5)$ & 518 & $2.6(2.4-2.8)$ & 1556 & $7.7(7.3-8.1)$ \\
\hline $61 \min +$ & 226 & $10.3(9.0-11.7)$ & 187 & $8.5(7.4-9.8)$ & 413 & I8.8 (17.1 - 20.7) \\
\hline
\end{tabular}

rates existed for women by travel distance to the closest hospital offering intrapartum obstetrical services $(\mathrm{p}=$ 0.70 ), with mortality rates of 8.8 (CI 8.4-9.2) and 7.8 (CI 5.8 - 10.6) respectively.

In terms of perinatal morbidity (Table 2), there was no significant change in birth fracture rates for any hospital type between the 1988 and 2012 (p = 0.35). Regional hospitals continue to have a slightly higher birth fracture rate than tertiary hospitals across all years. While cephalohematoma rates appear to decrease at both tertiary and regional hospitals from 1988 to 2007, they increase nearly back to baseline for tertiary hospitals by 2008-2012. Infant perinatal infection rates decreased more than 20-fold at regional hospitals between 1988-1992 and 2008-2012, and approximately 7 -fold at the IWK (Figure 2 ).

The morbidity trends observed for all births across Nova Scotia hold true for births of low risk infants. The perinatal infection rate at the tertiary hospital in 2008-2012 for low risk infants is approximately half the infection rate seen amongst all infants born at the same hospital during that epoch, reflecting an increased risk of infection with higher risk deliveries.

\section{Discussion and Conclusions}

Overall, infant perinatal morbidity and mortality outcomes have improved in Nova Scotia between 1988 and 2012. Decreasing rates of perinatal mortality for all births, but not low risk births only suggests that the largest improvements of care have occurred in the higher risk birth population. Effective referral of care through regionalization of maternal-newborn health services may have contributed to these improvements, as higher-risk pregnancies are identified earlier and referred appropriately to the tertiary centre, where Neonatal Intensive Care services are available. Changes in obstetrical care and neonatal resuscitation practices most likely played a large role in these mortality improvements. Further research into resuscitation trends and efficacy over time is warranted to determine why and how these improvements are occurring, and how we can continue to see these positive trends in the future.

A drastic reduction in neonatal infection rates was seen across the province. This trend coincides with the introduction of maternal Group B Streptococcus screening program in Nova Scotia, which was fully implemented by 2005 . The differences observed in cephalohematoma rates may reflect changes in operative delivery practices over time, as higher rates of cephalohematoma are seen with vacuum versus forceps deliveries. ${ }^{12}$ In Nova Scotia, a dramatic reduction in the number of operative vaginal deliveries being performed was observed between 1990-2000. ${ }^{1}$ Further research into changes in obstetrical practice throughout Nova Scotia in more recent years is warranted.

While the increasing proportion of deliveries occurring at Nova Scotia's single tertiary obstetrical centre correlates with the discontinuation of services at community hospitals, this increase also coincides with urban migration patterns of childbearing aged women (age 15-44) within Nova Scotia. ${ }^{13-16}$ While an increasing proportion of women in Nova Scotia need to travel more than one hour for intrapartum obstetrical care, there is currently no difference in perinatal mortality 
Table 2. Perinatal morbidity rates for all births and low risk births by hospital type and epoch

\begin{tabular}{|c|c|c|c|c|}
\hline & & \multicolumn{3}{|c|}{ Infant Perinatal Morbidity (ALL BIRTHS) } \\
\hline & & Fracture $(95 \% \mathrm{Cl})$ & Cephalohematoma $(95 \% \mathrm{Cl})$ & Infection $(95 \% \mathrm{Cl})$ \\
\hline \multirow[t]{3}{*}{$1988-1992$} & C & $0.21 \%(0.12-0.36)$ & $1.48 \%(1.21-1.81)$ & $7.20 \%(6.59-7.87)$ \\
\hline & $\mathrm{R}$ & $0.30 \%(0.24-0.37)$ & $1.63 \%(1.49-1.80)$ & $15.37 \%(|4.94-| 5.8 \mid)$ \\
\hline & $\mathrm{T}(\mathrm{IWK})$ & $0.13 \%(0.10-0.18)$ & $1.94 \%(1.79-2.10)$ & $13.23 \%(\mid 2.84-13.62)$ \\
\hline \multirow[t]{3}{*}{ 1993-1997 } & C & $0.25 \%(0.12-0.52)$ & $1.78 \%(1.35-2.34)$ & $8.04 \%(7.09-9.12)$ \\
\hline & $\mathrm{R}$ & $0.31 \%(0.25-0.38)$ & $1.39 \%(1.26-1.55)$ & $8.70 \%(8.36-9.06)$ \\
\hline & $\mathrm{T}(\mathrm{IWK})$ & $0.10 \%(0.07-0.15)$ & $1.76 \%(1.61-1.93)$ & $6.28 \%(5.99-6.58)$ \\
\hline \multirow[t]{3}{*}{$1998-2002$} & C & $*$ & $1.29 \%(0.78-2.12)$ & $6.27 \%(5.02-7.81)$ \\
\hline & $\mathrm{R}$ & $0.25 \%(0.19-0.33)$ & $0.82 \%(0.7 \mathrm{I}-0.95)$ & $8.28 \%(7.92-8.66)$ \\
\hline & $\mathrm{T}(\mathrm{IWK})$ & $0.18 \%(0.13-0.24)$ & $0.76 \%(0.65-0.88)$ & $5.99 \%(5.69-6.31)$ \\
\hline \multirow[t]{3}{*}{ 2003-2007 } & C & $0.00 \%$ & $0.00 \%$ & $*$ \\
\hline & $\mathrm{R}$ & $0.31 \%(0.24-0.40)$ & $0.49 \%(0.4 I-0.60)$ & $1.22 \%(1.08-1.39)$ \\
\hline & $\mathrm{T}(\mathrm{IWK})$ & $0.10 \%(0.07-0.15)$ & $0.25 \%(0.19-0.60)$ & $1.77 \%(1.61-1.95)$ \\
\hline \multirow[t]{5}{*}{$2008-2012$} & $\mathrm{C}$ & $0.00 \%$ & $0.00 \%$ & $0.00 \%$ \\
\hline & $\mathrm{R}$ & $0.35 \%(0.27-0.44)$ & $0.73 \%(0.62-0.86)$ & $0.70 \%(0.59-0.82)$ \\
\hline & $\mathrm{T}(\mathrm{IWK})$ & $0.19 \%(0.14-0.25)$ & $1.46 \%(1.32-1.62)$ & $1.94 \%(1.77-2.12)$ \\
\hline & & \multicolumn{3}{|c|}{ Infant Perinatal Morbidity (LOW RISK BIRTHS) } \\
\hline & & Fracture $(95 \% \mathrm{Cl})$ & Cephalohematoma (95\% Cl) & Infection $(95 \% \mathrm{Cl})$ \\
\hline \multirow[t]{3}{*}{$1988-1992$} & C & $0.20 \%(0.11-0.36)$ & $1.43 \%(1.14-1.80)$ & $6.85 \%(6.19-7.58)$ \\
\hline & $\mathrm{R}$ & $0.28 \%(0.22-0.36)$ & $1.61 \%(1.45-1.79)$ & $15.28 \%(|4.8|-\mid 5.77)$ \\
\hline & $\mathrm{T}(\mathrm{IWK})$ & $0.10 \%(0.07-0.15)$ & $1.98 \%(1.81-2.17)$ & $11.77 \%(11.36-12.20)$ \\
\hline \multirow[t]{3}{*}{$1993-1997$} & $\mathrm{C}$ & $0.25 \%(0.12-0.55)$ & $1.64 \%(1.20-2.23)$ & $7.73 \%(6.73-8.88)$ \\
\hline & $\mathrm{R}$ & $0.30 \%(0.23-0.38)$ & $1.34 \%(1.19-1.50)$ & $8.19 \%(7.83-8.57)$ \\
\hline & T (IWK) & $0.09 \%(0.05-0.13)$ & I.84\% (1.67-2.04) & $4.63 \%(4.36-4.92)$ \\
\hline \multirow[t]{3}{*}{$1998-2002$} & $\mathrm{C}$ & $0.00 \%$ & $0.81 \%(0.4 \mid-1.58)$ & $5.24 \%(4.02-6.80)$ \\
\hline & $\mathrm{R}$ & $0.23 \%(0.17-0.3 I)$ & $0.80 \%(0.69-0.94)$ & $7.77 \%(7.39-8.16)$ \\
\hline & $\mathrm{T}(\mathrm{IWK})$ & $0.18 \%(0.13-0.26)$ & $0.73 \%(0.62-0.86)$ & $4.06 \%(3.79-4.35)$ \\
\hline \multirow[t]{3}{*}{$2003-2007$} & C & $0.00 \%$ & $0.00 \%$ & $*$ \\
\hline & $\mathrm{R}$ & $0.31 \%(0.24-0.4 I)$ & $0.50 \%(0.4 \mathrm{I}-0.62)$ & $1.09 \%(0.95-1.26)$ \\
\hline & $\mathrm{T}$ (IWK) & $0.08 \%(0.05-0.13)$ & $0.26 \%(0.19-0.34)$ & $0.95 \%(0.82-1.09)$ \\
\hline \multirow[t]{3}{*}{$2008-2012$} & C & $0.00 \%$ & $0.00 \%$ & $0.00 \%$ \\
\hline & $\mathrm{R}$ & $0.32 \%(0.25-0.4 I)$ & $0.74 \%(0.62-0.87)$ & $0.50 \%(0.4 \mathrm{I}-0.62)$ \\
\hline & T (IWK) & $0.18 \%(0.13-0.25)$ & I.42\% (1.27-1.59) & $0.88 \%(0.76-1.02)$ \\
\hline
\end{tabular}

or morbidity outcomes for babies born to women who had to travel less than or more than one hour to access services. This suggests that increasing rural isolation from obstetrical services, as seen in Nova Scotia, has not been associated with increased infant perinatal mortality and morbidity. These findings support the conclusions drawn by VM Allen at al., who did not find population-level adverse consequences with the closure of community hospitals in Nova Scotia between 1988 and $2002 .{ }^{17}$ The large difference in perinatal mortality for infants born to women who traveled more than one hour to their actual hospital of delivery, as opposed to the closest hospital, suggests that appropriate referral of higher-risk pregnancies to the tertiary centre is occurring throughout Nova Scotia.

As changes in obstetrical service delivery continues to occur within Nova Scotia, an increasing proportion of women will need to travel further distances to access care. While this study supports the idea that increasing distances to care has no effect on infant perinatal mortality and morbidity outcomes, it does not address the psychosocial effects on pregnant women who are relatively isolated from care. Further qualitative research into these effects should be explored.

\section{Acknowledgements}

We thank the Reproductive Care Program of Nova 


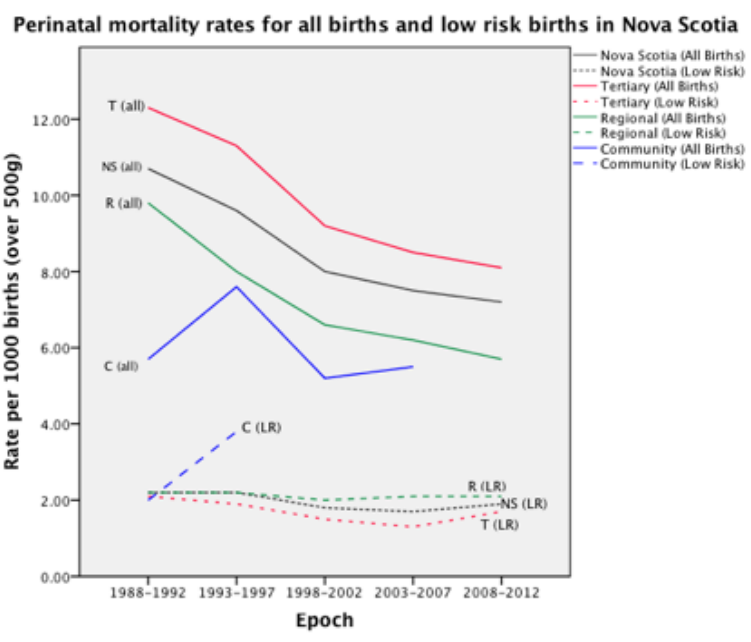

Figure I. Perinantal mortality rates in Nova Scotia for all and low risk births for Tertiary, Regional, and Community Hospitals.

Scotia for the use of the Nova Scotia Perinatal Atlee Database. Carly Langley held a summer studentship with funding provided by the CIHR Summer Research Studentship.

Authors have no conflicts of interest.

\section{References}

1. Reproductive Care Program of Nova Scotia. Nova Scotia Atlee Perinatal Database:annual report 2000. Halifax, Nova Scotia, 2005.

2. Fell DB, Joseph KS, Dodds L, Allen AC, Jangaard K, Van den Hof M. Changes in maternal characteristics in Nova Scotia, Canada from 1988 to 2001. Can J Public Health 2005;96(3):234-8.

3. Reproductive Care Program of Nova Scotia . Induction of labour in Nova Scotia: report from the provincial quality assessment review. 2012.

4. Reproductive Care Program of Nova Scotia. Best practices in the use of caesarian sections in Nova Scotia. 2007.

5. Joseph KS, Fahey J, Dendukuri N, Allen VM, O'Campo P, Dodds $\mathrm{L}$ et al.. Recent changes in maternal characteristics by socioeconomic status. J Obstet Gynaecol Can 2009;31(5):422-33.

6. The Perinatal Epidemiology Research Unit (of Nova Scotia). Nova Scotia Atlee Perinatal Database report of indicators 2002 - 2011. 2012;2.

7. Luo Z-C, Wilkins RP. Degree of rural isolation and birth outcomes. Paediatr Perinat Epidemiol 2008;22:341-9.

8. Robinson HE, O'Connell CM, Joseph KS, McLeod NL. Maternal outcomes in pregnancies complicated by obesity. Am J Obstet Gynecol 2005;106(6):1357-64.

9. Peddle LJ, Brown H, Buckley J, Dixon W, Kaye J, Muise M et al. Voluntary regionalization and associated trends in perinatal

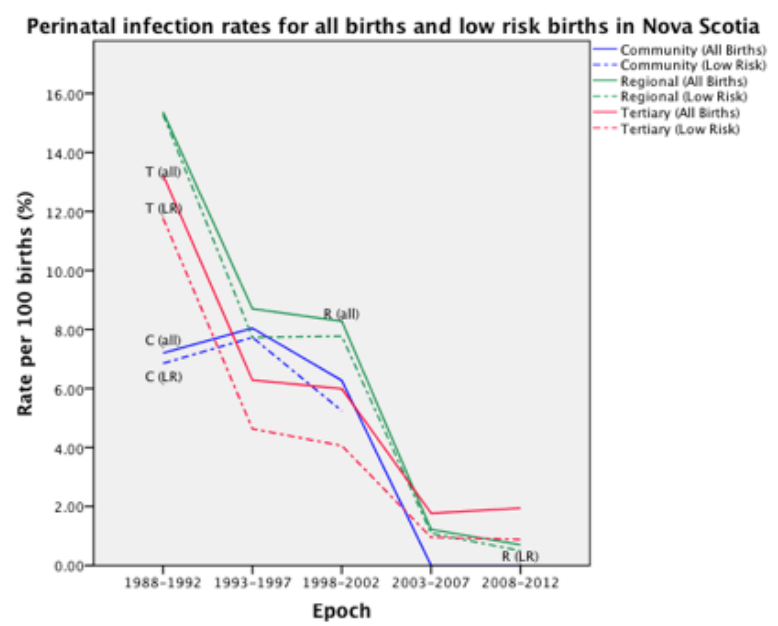

Figure 2. Perinantal infection rates in Nova Scotia for all and low risk births for Tertiary, Regional, and Community Hospitals.

care: the Nova Scotia Reproductive Care Program. Am J Obstet Gynecol 1983;145(2):170-6.

10. Joseph KS, Fahey J. Validation of the perinatal data in the Discharge Abstract Database of the Canadian Institute for Health Information. Chronic Dis Can 2009;29(3):96-100.

11. Fair M, Cyr M, Allen AC, Wen SW, Guyon G, MacDonald RC. An assessment of the validity of a computer system for probabilistic record linkage of birth and infant death records in Canada. Chronic Dis Can 2000;21(1):8-13.

12. Johanson R, Menon V. Vacume extraction versus forceps for assisted vaginal delivery. Cochrane Database Syst Rev 2000;(2):CD000224.

13. Statistics Canada. Population, urban and rural, by province and territory (Canada). Government of Canada. 2011 Census, 2011.

14. Statistics Canada. Focus on Geography Series, 2011 Census. Statistics Canada Catalogue no. 98-310-XWE2011004. Ottawa, Ontario. Analytical products, 2011 Census. 2012.

15. Statistics Canada. 2007. Halifax, Nova Scotia (Code1209034) (table). 2006 Community Profiles. 2006 Census. Statistics Canada Catalogue no. 92-591-XWE. Ottawa. Released March 13, 2007. (accessed November 20, 2014).

16. Statistics Canada. 2002. Halifax, Nova Scotia (table). 2001 Community Profiles. 2006 Census. Statistics Canada Catalogue no. 92-591-XWE. Ottawa. 2013. (accessed November 2).

17. Allen VM, Jilwah N, Joseph KS, Dodds L, O'Connell CM, Luther ER et al. The influence of hospital closures in Nova Scotia on perinatal outcomes. J Obstet Gynaecol Can 2004;26(12):107785.

18. Canadian Institute for Health Information. Giving birth in Canada - a regional profile. Canadian Institute for Health Information. 2004.

19. Allerdings M, Chen XK, Cullen D, Feeney W, Herold S, Hewitt $\mathrm{M}$ et al. Hospital births in Canada - a focus on women living in rural and remote areas. Canadian Institute for Health Information. 2013. 